\title{
MAKING OF ALLOY 706 INGOT FOR GAS TURBINE PARTS
}

\author{
Sou Ueda*, Mitsunori Funazaki*, Junichi Tira*, Hitohisa Yamada ${ }^{* *}$ \\ ${ }^{*}$ Muroran Plant, ${ }^{* *}$ Muroran Research Laboratory \\ The Japan Steel Works, LTD. \\ 4 Chatsu-machi, Muroran, Hokkaido 051-8505, Japan
}

\begin{abstract}
In general, Alloy 706 ingots for gas turbine parts are made by the VIM-ESR-VAR triple melt process due to strong segregation tendency of the alloy ${ }^{1}$. From the viewpoint of cost and delivery time saving, the Japan Steel Works has applied the VIM-ESR double melt process. To optimize ESR condition, relationships between melt rate and local solidification time, and between chemical composition and viscosity of slag have been investigated. The calculation shows that there is a range of melt rate which minimizes the local solidification time, and a melt rate between 300 and $400 \mathrm{~kg} / \mathrm{h}$ is considered adequate for a dia $650 \mathrm{~mm}$ ingot. Increase in $\mathrm{CaF}_{2}$ content in $\mathrm{CaF}_{2}-\mathrm{Al}_{2} \mathrm{O}_{3}-\mathrm{CaO}$ slag system is found to reduce the viscosity of slag, and a slag with high $\mathrm{CaF}_{2}$ content, i.e. with low viscosity, is used for industrial scale production. With the optimized ESR conditions obtained in the present study, a dia $650 \mathrm{~mm}$ Alloy 706 ingot has successfully been produced with minimum segregation by the VIM-ESR double melt process.
\end{abstract}

Superalloys 718, 625, 706 and Various Derivatives Edited by E.A. Loria

TMS (The Minerals, Metals \& Materials Society), 2001 


\section{Introduction}

Alloy 706 has superior strength at high temperatures, and is commonly applied to gas turbine parts. The specification of chemical composition is shown in Table I. In general. Alloy 706 ingots are made by the VIM-ESR-VAR triple melt process. The necessity of the triple melt process (double remelting) comes from the strong segregation tendency of the alloy: From the viewpoint of cost and delivery time saving. the double melt process without VAR has been considered. However. Alloy 706 FSR ingots that we produced with conventional ESR conditions and slag composition indicated strong center segregation as shown in Figure 1. The objective of the present study is to establish process conditions of the VIM- ESR double melting for minimum segregation. To accomplish this. the relationship among melt rate, mold size and local solidification time has been investigated. Also. the relationship between chemical composition and viscosity of $\mathrm{CaF}_{2}-\mathrm{Al}_{2} \mathrm{O}_{3}-\mathrm{CaO}$ slag system has been examined. Based on these investigations, then, an industrial scale (dia $650 \mathrm{~mm}$ ) ingot has been produced. With the results of quality evaluation of the industrial size ingot. optimum process conditions will be discussed. Table II summarizes characteristics of triple and double melt process.

Table I Chemical Composition of Alloy 706 (weight \%)

\begin{tabular}{|c|c|c|c|c|c|c|c|c|c|}
\hline & $\mathrm{C}$ & $\mathrm{Si}$ & $\mathrm{Mn}$ & $\mathrm{Ni}$ & $\mathrm{Cr}$ & $\mathrm{Ti}$ & Al & B & $\mathrm{Nb}+\mathrm{Ta}$ \\
\hline Spec.(AMS) & $\leqq 0.06$ & $\leqq 0.35$ & $\leqq 0.35$ & 39.0 & 14.5 & 1.50 & $\leqq 0.40$ & $\leqq 0.006$ & 2.50 \\
\hline & & & & 144.0 & $/ 17.5$ & 12.00 & & & 13.00 \\
\hline
\end{tabular}

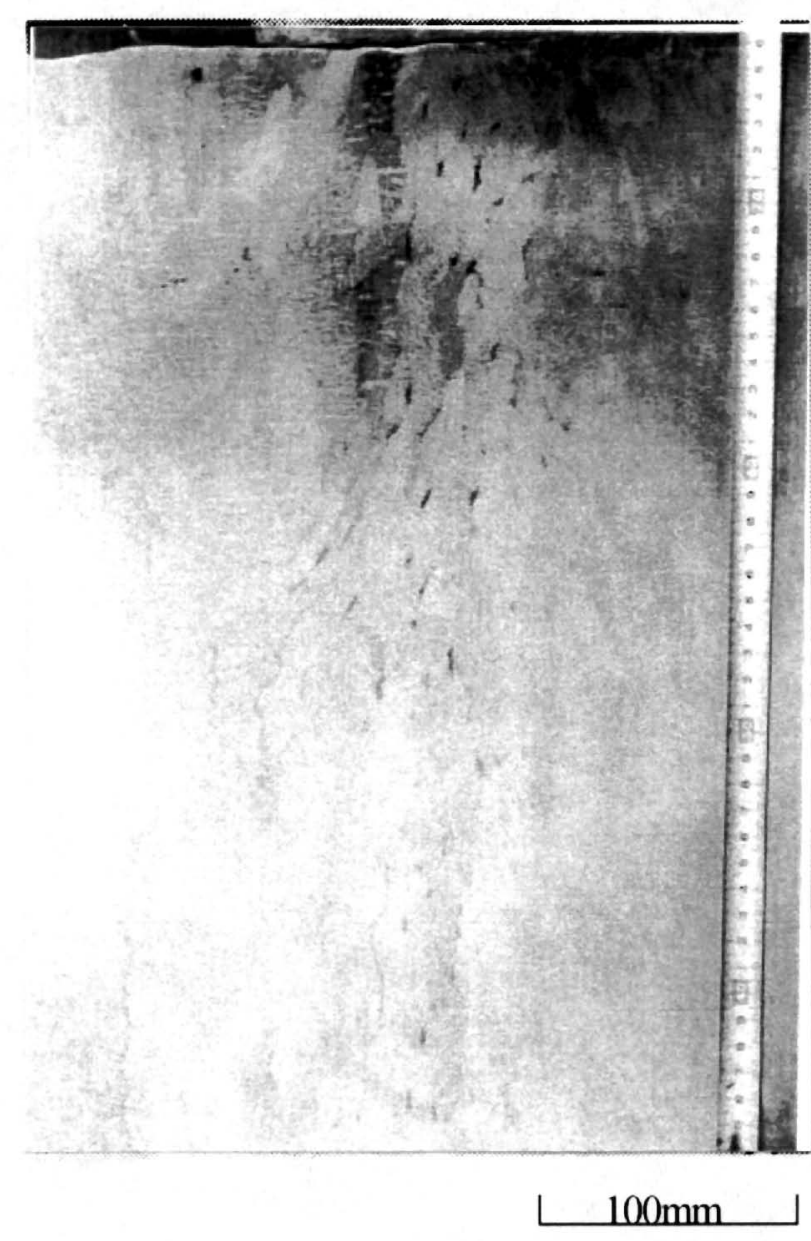

Figure 1: Macrophotograph of cross section of etched Alloy 706 ESR ingot produced with conventional ESR conditions and slag composition. Strong center segregation is observed. 
Table II the Characteristics of Triple and Double Melt Processes

\begin{tabular}{|c|c|c|l|}
\hline Macro segregation & $\begin{array}{c}\text { VIM-ESR-VAR } \\
\text { (triple melt) }\end{array}$ & $\begin{array}{c}\text { VIM-ESR } \\
\text { (double melt) }\end{array}$ & \\
\hline $\begin{array}{c}\text { Chemical } \\
\text { composition control }\end{array}$ & $-\begin{array}{l}\text { VAR is sperior in cooling rate to ESR. } \\
\text { and is effective in prevention of center } \\
\text { segregation. }\end{array}$ \\
\hline $\begin{array}{c}\text { Ingot surface } \\
\text { condition }\end{array}$ & - & $\begin{array}{l}\text { ESR is difficult to control Al and Ti } \\
\text { content because of reaction between } \\
\text { slag and metal and between metal and } \\
\text { oxygen in the atomsphere. }\end{array}$ \\
\hline Cost & - & $\begin{array}{l}\text { Surface condition of ESR ingot is good } \\
\text { due to being covered by slag skin. }\end{array}$ \\
\hline
\end{tabular}

\section{Investigation of Process Conditions}

The macro segregation occurs because alloy elements such as $\mathrm{Nb}$ or $\mathrm{Ti}$ concentrate in unsolidified part during solidification. When the solute-enriched liquid parts are relatively small, they accumulate locally and the accumulation causes discontinuous solidification. Once the solute-enriched liquid parts get large they flow and form center segregation. Therefore we must choose the ESR conditions to disperse the solute-enriched liquid parts.

From the ESR conditions of the previous melts of Alloy 706. we calculated the local solidification time at the center of the ingot and the depth of the molten pool. The mold diameter was varied from $450 \mathrm{~mm}$ to $1050 \mathrm{~mm}$. Figure 2 shows the degree of center segregation of the ingots with the calculated local solidification time and depth of molten pool. It is clear that the segregation is reduced with decreasing local solidification time and /or the depth of molten pool. We. therefore. investigated the influences of the melt rate and the thickness of slag skin on the local solidification time

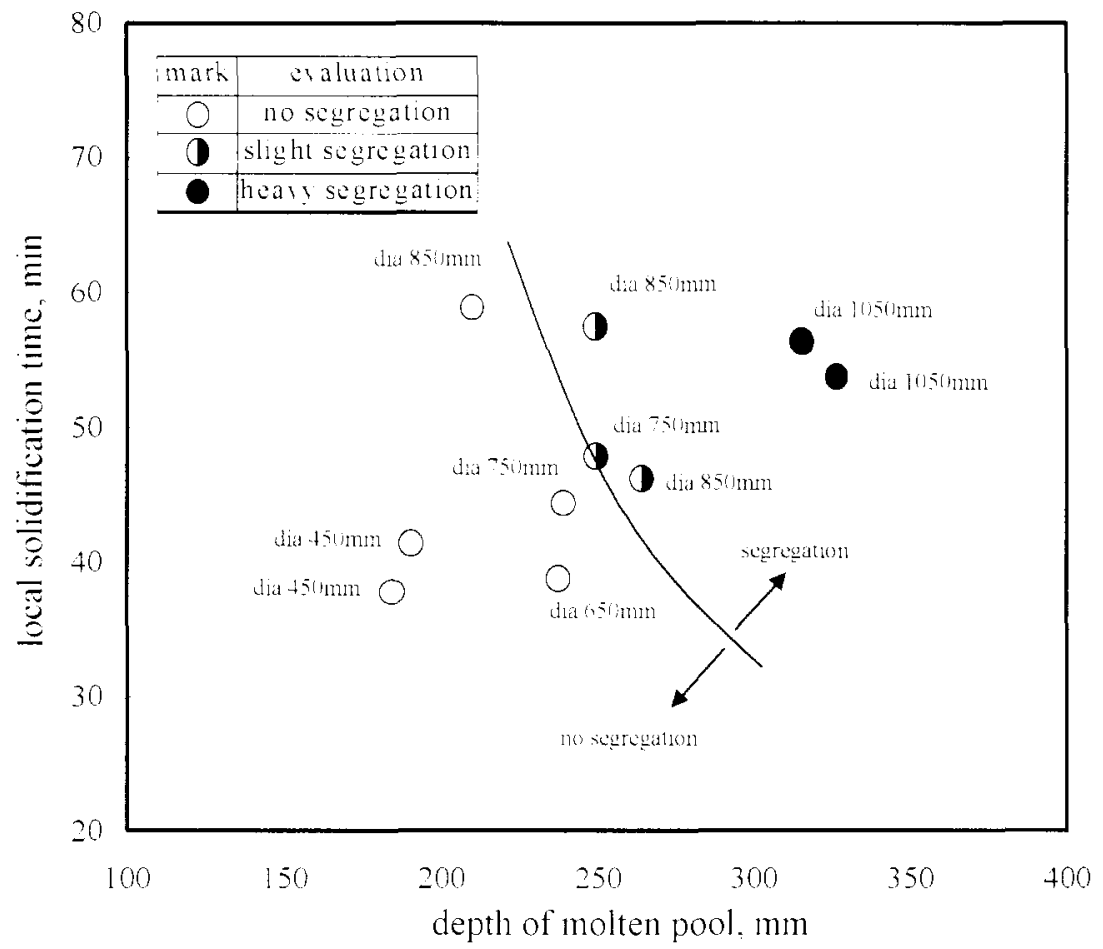

Figure 2: Occurrence of center segregation in Alloy 706 ingots. I.ocal solidification time and depth of molten pool were calculated from the ESR conditions 
First we calculated the local solidification time as a function of the melt rate with different mold diameters. The calculation was conducted on the basis of direct finite difference method. The calculated local solidification time was verified with values obtained from measurement of dendrite arm spacing of solidification structure. The results of calculation of dia $750 \mathrm{~mm}$ and $650 \mathrm{~mm}$ ingots are shown in Figure 3 with curves for dia $500 \mathrm{~mm}$ and $300 \mathrm{~mm}$ ingots reproduced from the literature ${ }^{21}$. While the local solidification time increases as the diameter of ingot increases. all curves similarly show that there is a range of melt rate which minimizes the local solidification time. From this calculation. the range of melt rate between 300 and $400 \mathrm{~kg} / \mathrm{h}$ was targeted for a dia $650 \mathrm{~mm}$ ingot.

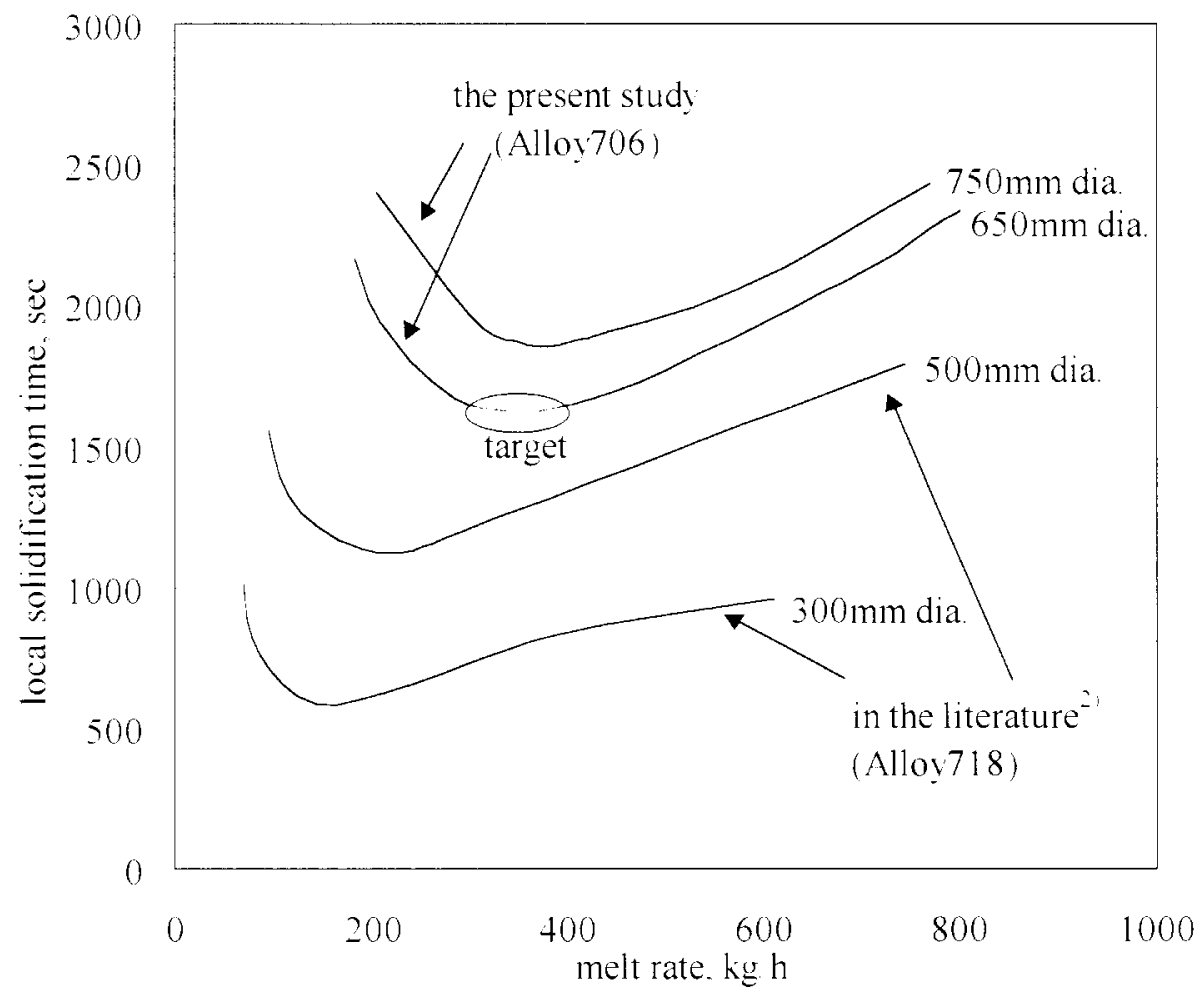

Figure 3: Relationship between local soliditication time of center portion of the ingot and melt rate in Alloys 706 and 718.

Next. the effect of the thickness of slag skin was investigated also by calculation. The calculation shows that the depth of molten pool increases with increasing the thickness of slag skin when the thickness is $10 \mathrm{~mm}$ or less. When the slag skin is over $10 \mathrm{~mm}$. the effect of the thickness is not significant. Since the increase in the thickness of slag skin causes increase in the depth of molten pool. accordingly increase in the local solidification time, it is important to select the slag composition to keep the thickness of slag skin small. We, therefore. tried to be lower the viscosity of slag to make slag skin thin ${ }^{3-5}$. and we measured the viscosity of various compositions at $\mathrm{CaF}_{2}-\mathrm{Al}_{2} \mathrm{O}_{3}-\mathrm{CaO}$ system. From a regression analysis of the data. the following relationship between the viscosity $\mu$ (poise) at $1600 \mathrm{C}$ and the contents of $\mathrm{CaO}$ and $\mathrm{Al}_{2} \mathrm{O}_{3}$ in the slag was obtained.

$$
\log \mu=0.005[\% \mathrm{CaO}]+0.029\left[\% \mathrm{Al}_{2} \mathrm{O}_{3}\right]-1.179
$$

This equation suggests that decreasing the contents of $\mathrm{CaO}$ and $\mathrm{Al}_{2} \mathrm{O}_{3}$ reduce the viscosity of the slag. Besides the viscosity: we chose the slag composition so that the melting point of the slag is low enough for ESR operation. 


\section{Industrial Scale Production}

\section{Process Conditions}

Detailed ESR conditions for industrial scale production are listed in table III. The diameter of the ingot is $650 \mathrm{~mm}$. the height is $1.700 \mathrm{~mm}$, and weight is $4.600 \mathrm{~kg}$. For prevention of Ti loss due to slag-metal reaction. $\mathrm{TiO}_{2}$ is added to the slag. The voltage swing is set larger than that for normal low alloy steel so that the immersion depth in the slag of the electrode can be kept as shallow as possible ${ }^{3}$. To prevent $\mathrm{Al}$ and Ti from oxidation. Ar is chosen as atmosphere. Table IV describes our ESR facility: The dia $650 \mathrm{~mm}$ ingot was produced with this facility using power supplies in separate. The electrode for ESR was made with our 5 tVIM.

Table III ESR Condition for Alloy 706 Melt

\begin{tabular}{|c|c|}
\hline mold size & $680 \mathrm{~mm}$ dia. \\
\hline ingot size & $650 \mathrm{~mm}$ dia. $1,700 \mathrm{~mm} \mathrm{H}$ \\
\hline ingot weight & $4,600 \mathrm{~kg}$ \\
\hline melt rate & $300-400 \mathrm{~kg} \mathrm{~h}$ \\
\hline slag system & $\mathrm{CaF}_{2}-\mathrm{Al}_{2} \mathrm{O}_{3}-\mathrm{CaO}-\mathrm{TiO}_{2}-\mathrm{MgO}$ \\
\hline slagcap height & $150-250 \mathrm{~mm}$ \\
\hline voltage swing & $2.5-3.5 \mathrm{~V}$ \\
\hline atmosphere & $\mathrm{Ar}$ \\
\hline treatment of electrode & grinding \\
\hline fill ratio & $0.6-0.7$ \\
\hline starting method & cold start \\
\hline
\end{tabular}

Table IV Description of ISW's ESR Facility

\begin{tabular}{|c|c|c|}
\hline name & \multicolumn{2}{|c|}{ 100tESR } \\
\hline type & \multicolumn{2}{|c|}{ 2heads2stations } \\
\hline power supply & \multicolumn{2}{|c|}{$5,400 \mathrm{KVA}(2.700 \times 2)$} \\
\hline \multirow{3}{*}{ capacity } & connect power supply in palallel & use power supplies in separate \\
\cline { 2 - 3 } & Static & static, withdrawal \\
\cline { 2 - 3 } & 100 tons & 20 tons \\
\hline max ingot size & $\phi 1,800 \times 5,000 \mathrm{~mm}$ & $1,050 \times 3,300 \mathrm{~mm}$ \\
\hline $\begin{array}{c}\text { max. slag } \\
\text { melt }\end{array}$ & \multicolumn{2}{|c|}{$3.300 \mathrm{~kg}$} \\
\hline atmosphere & \multicolumn{2}{|c|}{ dry air, inert gas } \\
\hline
\end{tabular}

\section{Quality Lvaluation}

The ESR operation with the conditions shown in Table III was quite stable and completed with no trouble. Figure 4 shows the appearance of ingot obtained. The surface of ingot was smooth and the slag skin was thin. The chemical composition near the surface of ingot at top portion is shown in Table $V$. The content of each element is in the aimed range. 


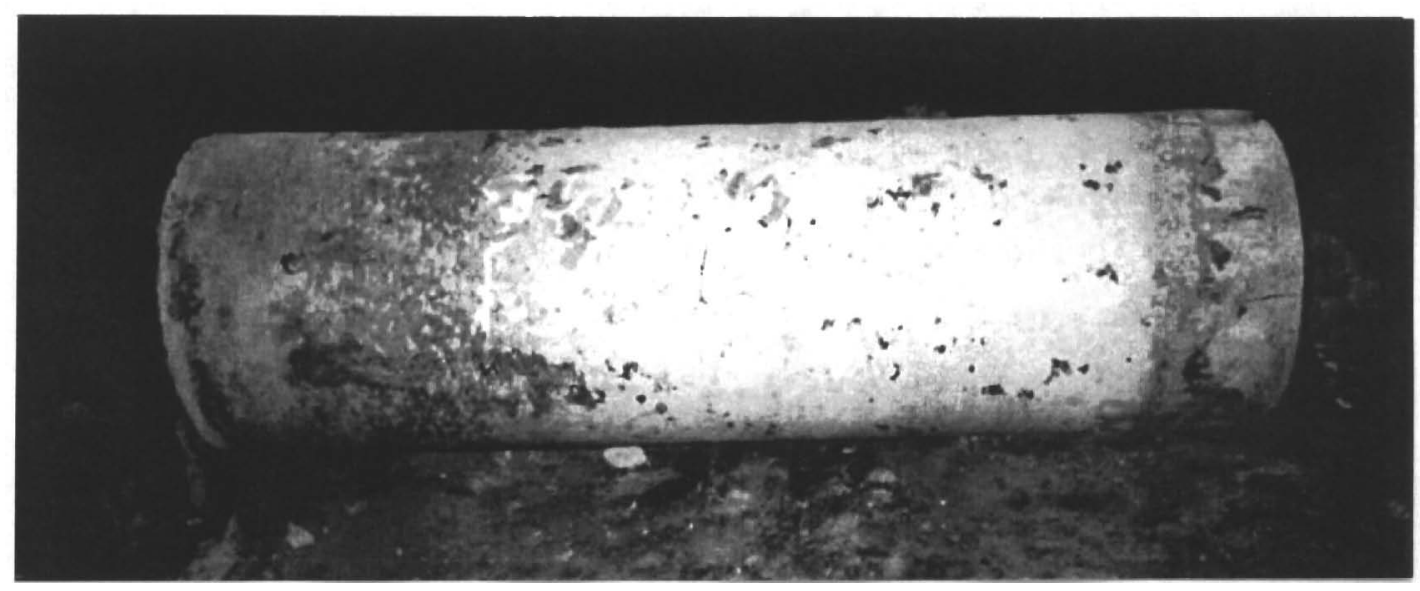

Figure 4: Appearance of double melted Alloy 706 ingot.

Table V Chemical Composition of Double Melted Alloy 706 Ingot (weight \%)

\begin{tabular}{|c|c|c|c|c|c|c|c|c|c|}
\hline & $\mathrm{C}$ & $\mathrm{Si}$ & Mn & $\mathrm{Vi}$ & $\mathrm{Cr}$ & $\mathrm{Ti}$ & $\mathrm{Al}$ & B & $\mathrm{Nb}-\mathrm{Ta}$ \\
\hline Spec. (AMS) & $<0.06$ & $<0.35$ & 00.35 & $\begin{array}{l}39.00 \\
44.00\end{array}$ & $\begin{array}{l}14.50 \\
17.50\end{array}$ & $\begin{array}{l}1.50 \\
2.00\end{array}$ & $<0.40$ & $<0.006$ & $\begin{array}{l}2.50 \\
3.30\end{array}$ \\
\hline production & 0.009 & 0.01 & 0.02 & 1.69 & 15.79 & 1.7 & 0.21 & 0.0031 & 3.02 \\
\hline
\end{tabular}

The ingot was forged to a disc shape. and then heat treated. After machining. we checked the macro structure and the distribution of each element. Figure 5 is a schematic illustration of the disc. The diameter of the disc is $1.285 \mathrm{~mm}$ and the thickness is $185 \mathrm{~mm}$. The core block was taken off and examined as well as the disc itself.

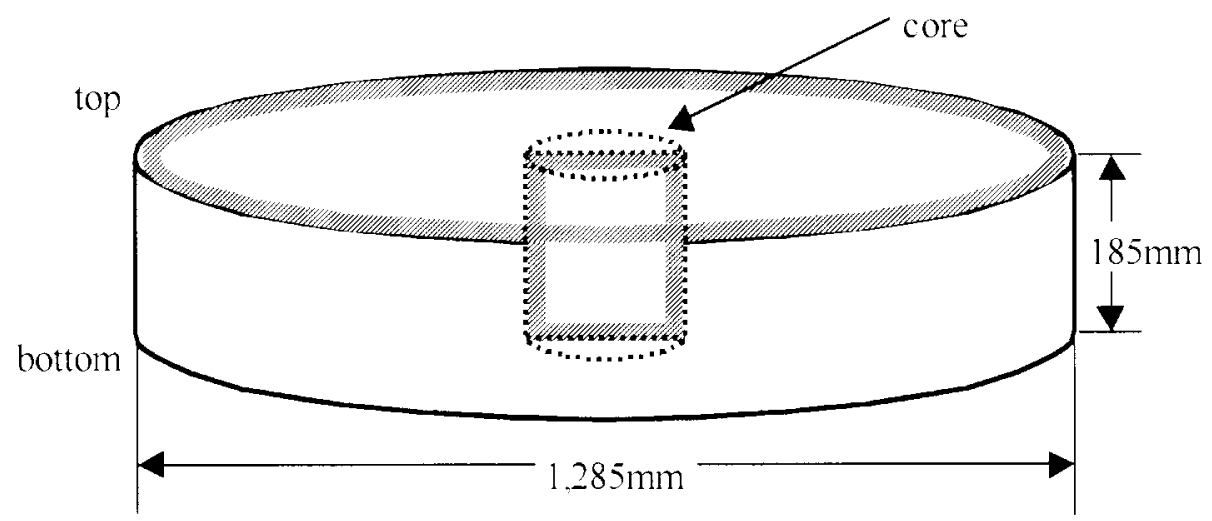

Figure 5: Schematic of the forged and machined disc. 
Macro structure of two sections were observed. The one is horizontal section at top side of the disc and the other is the vertical cross section of the taken core block. The core block was cut half so that the macro structure of very center of the disc can be investigated. Figures 6 and 7 show the macro structure of the horizontal section of the top side and that of the vertical cross section of the core block. respectively. The both macro structures were good and no segregation was found.

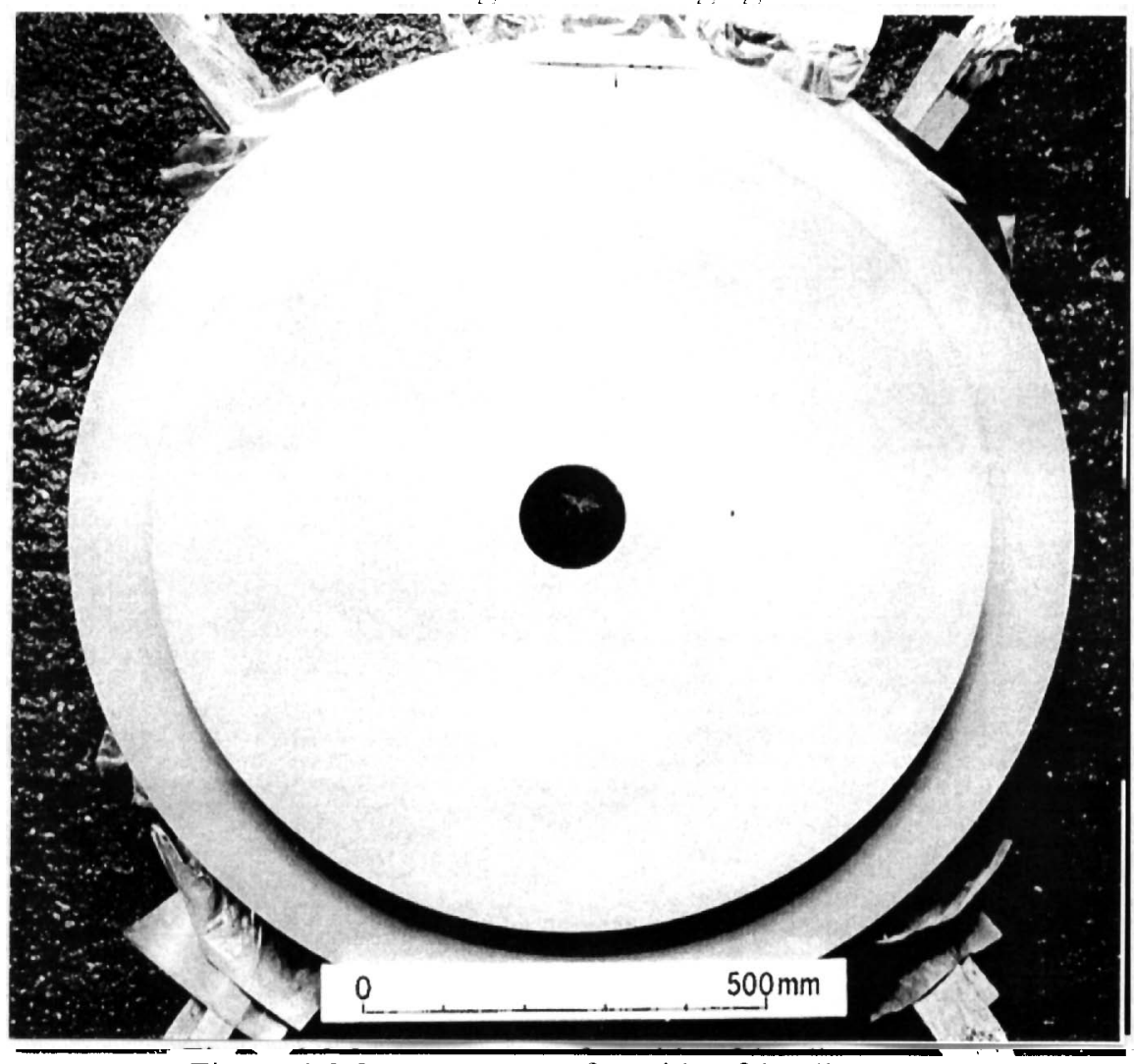

Figure 6: Macrostructure of topside of the disc.

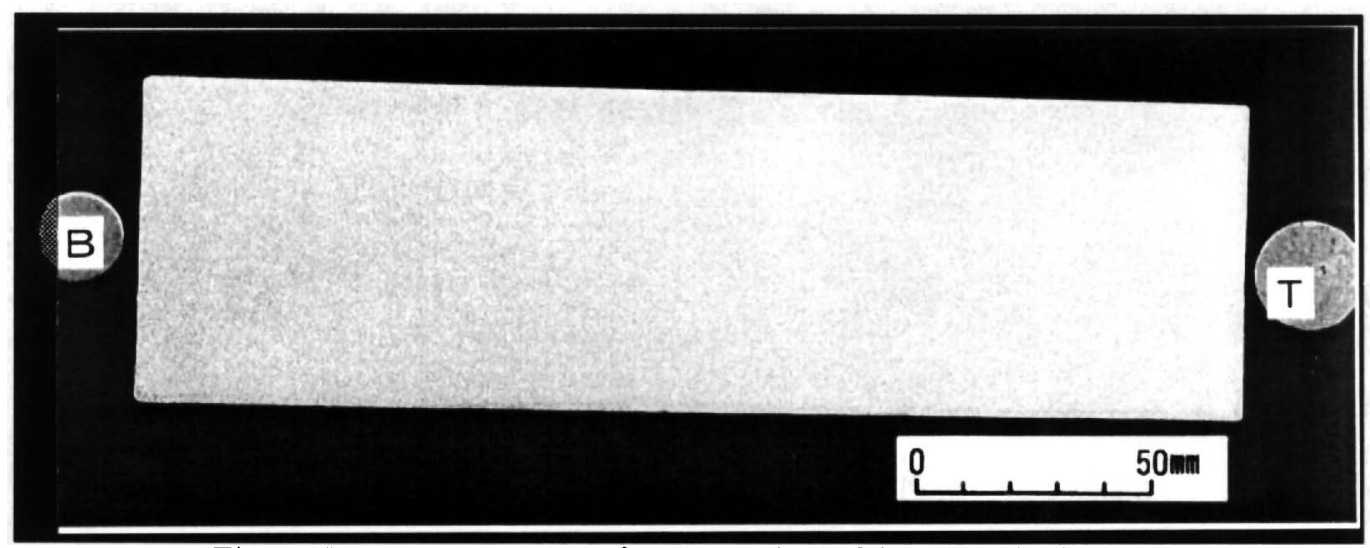

Figure 7: Macrostructure of cross section of the core block. 
Figure 8 shows the concentration variation of ten elements (C. Si Mn. Ni. Cr, Al, Ti, Nb, B and O) with respect to position. top. 1/4T, 1/2T, 3/4T and bottom. in the core block.
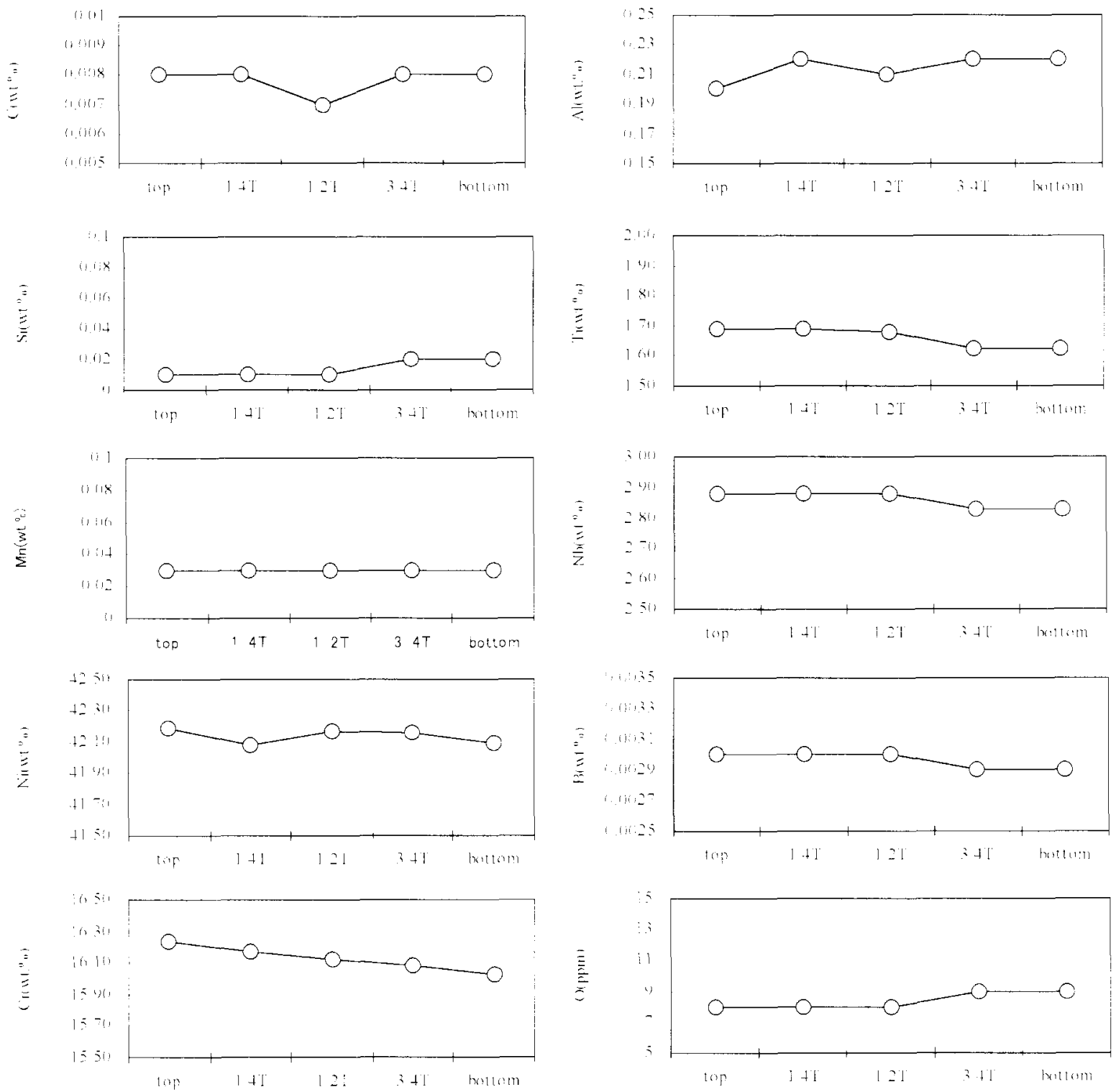

Figure 8: Variation in concentration of alloy element.

For all the analyzed elements, the variation is small throughout the core block. While the concentration of Ti which is active with oxygen tends to be lower at bottom than at top. the variation is not large enough to affect mechanical properties at all. Mechanical properties of Alloy 706 large forging are presented elsewhere in this proceedings.

\section{Discussion}

A dia $650 \mathrm{~mm}$ ingot of Alloy 706 with no segregation was successfully produced by the VIM-ESR double melt process. The actual melt rate of the melt is plotted in Figure 9 with those of the previous melts which were performed with three different diameters of mold. The melt rate of each heat is plotted along the curve of calculated local solidification time. Square marks denote the previous melt in which the conventional slag with low $\mathrm{CaF}_{2}$ content and nomal viscosity was used. Circle mark represents the present melt using the new slag of which $\mathrm{CaF}_{2}$ content is high and viscosity is low. 
Solid marks mean that center segregation was observed and open marks mean that there was no segregation. A half solid mark indicates that slight segregation was found. According to the relationship between diameter of mold and local solidification time, the range of melt rate in which no segregation is expected is considered to decrease with increasing the diameter. From this point of view. two dotted lines in Figure 9 were drawn. The intersection of the two lines indicates critical conditions of melt rate and mold diameter for production of large ingots without segregation. In other words, it may be possible to increase the diameter of ingot up to 850 or $900 \mathrm{~mm}$ even with the VIMESR double melt process. if ESR conditions are completely optimized and controlled.

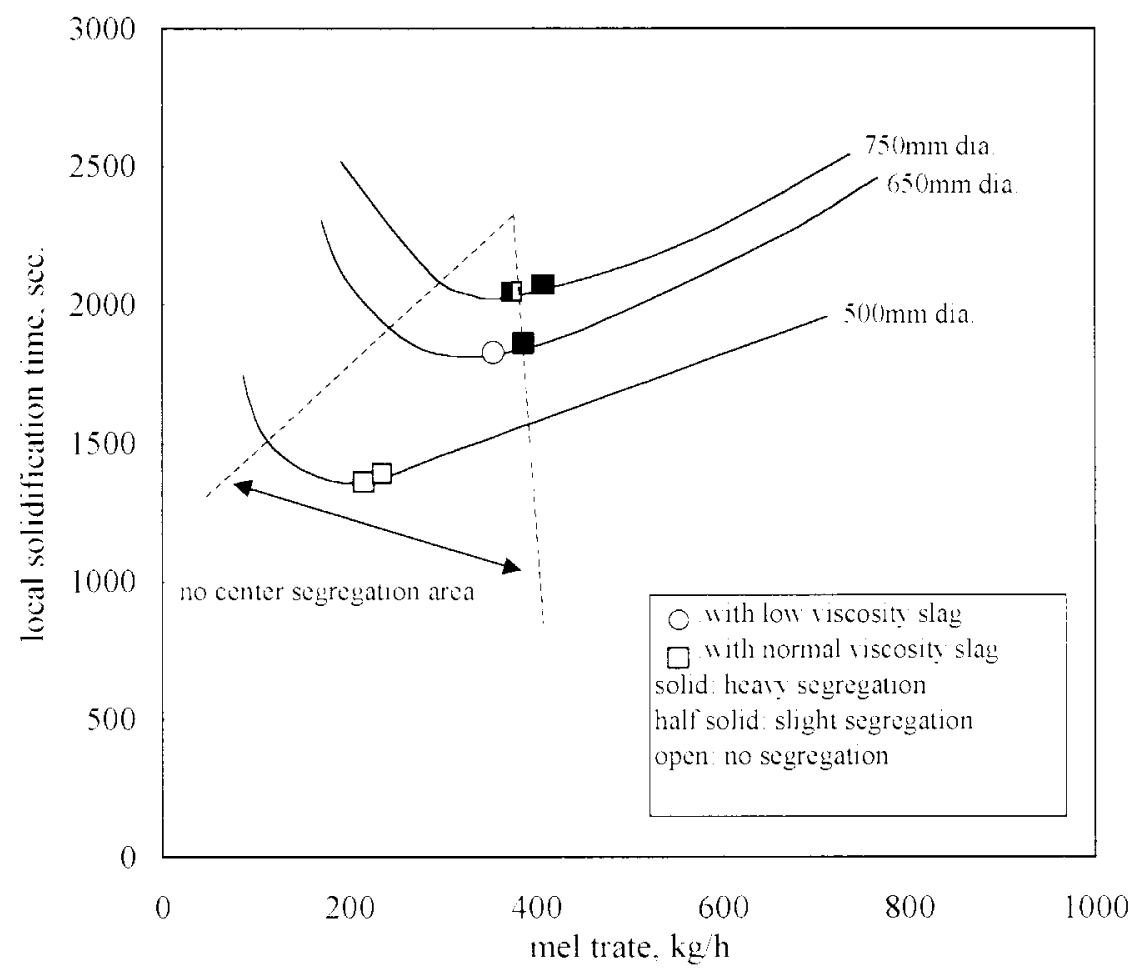

Figure 9: Relationship between local solidification time of center portion of the ingot and melt rate. ESR conditions should be between the two dotted lines to avoid the center segregation in production of Alloy 706 .

\section{Conclusions}

1. The local solidification time was calculated as a function of melt rate with different mold diameters. The calculation shows a range of melt rate in which the local solidification time is minimum. while the local solidification time increases as the diameter of ingot increases. A melt rate between 300 and $400 \mathrm{~kg} / \mathrm{h}$ is considered adequate for dia $650 \mathrm{~mm}$ Ingots.

2. Increase in $\mathrm{CaF}_{2}$ content in $\mathrm{CaF}_{2}-\mathrm{Al}_{2} \mathrm{O}_{3}-\mathrm{CaO}$ system lowers the viscosity of the slag. A slag with low viscosity is considered to make slag skin thickness thin. reducing the degree of segregation. 3. With the optimized ESR conditions obtained from the present study, a dia $650 \mathrm{~mm}$ Alloy 706 ingot was successfully produced with minimum segregation by the VIM-ESR double melt process which is more productive than the VIM-ESR-VAR triple melt process. 


\section{References}

1. Ann D. Helms. Charles B. Adasczik. and Laurence A. Jackman, "Extending the Size Limits of Cast/Wrought Superalloy Ingots." Superalloys 1996. ed. R. D. Kissinger et al.. (TMS. 1996).427-433.

2. S. Sasayama. "Progress in Remelting Process." Nishiyamakinenkouza (1993). 223-245.

3. G. Hoyle. Electroslag Processes -Principles and Practice-(Essex. UK: Applied Science Publishers. 1983). 10-15. 26-28. 55-60.

4. W. E. Duckworth and G. Hoyle. Electro-Slag Refining ( London. UK: Chapman and Hall LTD. 1969). 27. 36-40.

5. A. Ito et al. "Macro-Segregation Control of Ni-base Superalloy by Electro-Slag Remelting." CAMP-ISIJ, Vol. 9(1996), 80.

6. S. Ueda et al., "Making of Alloy 706 Ingot for Gas Turbine Parts." CAMP-ISI., Vol. 11(1998). 995. 